\title{
Exposure to Secondhand Smoke Impairs Fracture Healing in Rats
}

\author{
Hildemberg A. R. Santiago PhD, Ariane Zamarioli PhD, \\ Manoel D. Sousa Neto PhD, Jose B. Volpon MD, PhD
}

Received: 29 June 2016/Accepted: 18 November 2016/Published online: 30 November 2016

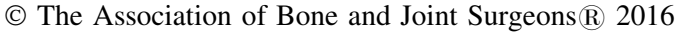

\begin{abstract}
Background Nonsmokers may be affected by environmental tobacco smoke (secondhand smoke), but the effects of such exposure on fracture healing have not been well studied.

Questions/purposes To explore the possible effects of passive inhalation of tobacco smoke on the healing of a diaphyseal fracture in femurs of rats. We hypothesized that

Each author certifies that neither he or she, nor any member of his or her immediate family, have funding or commercial associations (consultancies, stock ownership, equity interest, patent/licensing arrangements, etc) that might pose a conflict of interest in connection with the submitted article.

All ICMJE Conflict of Interest Forms for authors and Clinical Orthopaedics and Related Research ${ }^{\mathbb{R}}$ editors and board members are on file with the publication and can be viewed on request. Clinical Orthopaedics and Related Research ${ }^{\mathbb{R}}$ neither advocates nor endorses the use of any treatment, drug, or device. Readers are encouraged to always seek additional information, including FDAapproval status, of any drug or device prior to clinical use. Each author certifies that his or her institution approved the animal protocol for this investigation and that all investigations were conducted in conformity with ethical principles of research. This work was performed at the School of Medicine of Ribeirão Preto, University of São.
\end{abstract}

H. A. R. Santiago, A. Zamarioli

Laboratory of Bioengineering, School of Medicine of Ribeirão

Preto, University of São Paulo, Ribeirão Preto, Brazil

M. D. Sousa Neto

Dental School of Ribeirão Preto, University of São Paulo, Ribeirão Preto, Brazil

J. B. Volpon ( $\square)$

School of Medicine of Ribeirão Preto, University of São Paulo, Av. Bandeirantes, 3900, Ribeirão Preto, SP 14049-900, Brazil e-mail: hc.ortopedia@gmail.com secondhand exposure to tobacco smoke adversely affects fracture healing.

Methods A mid-diaphyseal fracture was created in the femur of 41 female Wistar rats and fixed with an intramedullary metallic pin; 14 rats were excluded (nine for inadequate fractures and five for $\mathrm{K}$ wire extrusion). Tobacco exposure was provided by a smoking machine on a daily basis of four cigarettes a day. Each cigarette yielded $10 \mathrm{mg}$ tar and $0.8 \mathrm{mg}$ nicotine, and was puffed by alternating injections of fresh air for 30 seconds and smoke air for 15 seconds. The smoke exposure was previously adjusted to provide serum levels of cotinine similar to human secondhand tobacco exposure. Cotinine is a predominant catabolite of nicotine that is used as a biological biomarker for exposure to tobacco smoke. In one group $(\mathrm{n}=11)$, the animals were intermittently exposed to tobacco smoke before sustaining the fracture but not afterward. In another group $(\mathrm{n}=7)$, the exposure occurred before and after the fracture. The control group $(\mathrm{n}=9)$ was shamexposed before and after the fracture. We evaluated the specimens 28 days after bone fracture. The callus quality was measured by dual-energy $\mathrm{x}$-ray absorptiometry (bone mineral density [BMD], bone mineral content [BMC], and callus area), $\mu \mathrm{CT}$ (callus volume and woven bone fraction), and mechanical bending (maximum force and stiffness).

Results Tobacco exposure resulted in delayed bone callus formation, which is represented by decreased BMD (Control: $0.302 \pm 0.008 \mathrm{~g} / \mathrm{cm}^{2}$ vs Preexposed: $0.199 \pm 0.008 \mathrm{~g} /$ $\mathrm{cm}^{2}$ and Pre- and Postexposed: $0.146 \pm 0.009 \mathrm{~g} / \mathrm{cm}^{2}$; mean difference $=0.103 \mathrm{~g} / \mathrm{cm}^{2}, 95 \% \mathrm{CI}, 0.094-0.112 \mathrm{~g} / \mathrm{cm}^{2}$ and mean difference $=0.156 \mathrm{~g} / \mathrm{cm}^{2}, 95 \% \mathrm{CI}, 0.147-0.167 \mathrm{~g} /$ $\mathrm{cm}^{2} ; \mathrm{p}<0.01$ ), BMC (Control: $0.133 \pm 0.005 \mathrm{~g}$ vs Preexposed: $0.085 \pm 0.0034 \mathrm{~g}$ and Pre- and Postexposed: $0.048 \pm 0.003 \mathrm{~g}$; mean difference $=0.048 \mathrm{~g}, 95 \% \mathrm{CI}$, $0.045-0.052 \mathrm{~g}$ and mean difference $=0.085 \mathrm{~g}, 95 \% \mathrm{CI}$, 
0.088-0.090 g; p < 0.01), callus volume (Control: $7.656 \pm$ $1.963 \mathrm{~mm}^{3}$ vs Preexposed: $17.952 \pm 1.600 \mathrm{~mm}^{3}$ and Preand Postexposed: $40.410 \pm 3.340 \mathrm{~mm}^{3}$; mean difference $=$ $-10.30 \mathrm{~mm}^{3}, 95 \% \mathrm{CI},-14.12$ to $6.471 \mathrm{~mm}^{3}$ and mean difference, $-32.75 \mathrm{~mm}^{3}, 95 \% \mathrm{CI},-36.58$ to $28.93 \mathrm{~mm}^{3}$; $\mathrm{p}<0.01$ ), woven bone fraction (Control: $42.076 \pm 3.877 \%$ vs Preexposed: $16.655 \pm 3.021 \%$ and Pre- and Postexposed: $8.015 \pm 1.565 \%$, mean difference $=0.103 \%, 95 \%$ CI, $0.094-0.112 \%$ and mean difference $=0.156 \%, 95 \% \mathrm{CI}$, 0.147-0.166\%; $\mathrm{p}<0.01$ ), maximum force (Control: $427.122 \pm 63.952$ N.mm vs Preexposed: $149.230 \pm 67.189$ N.mm and Pre- and Postexposed: $123.130 \pm 38.206$ N.mm, mean difference $=277.9$ N.mm, 95\% CI, 201.1-354.7 N.mm and mean difference $=304$ N.mm, 95\% CI, 213.2394.8 N.mm; $\mathrm{p}<0.01$ ) and stiffness (Control: $491.397 \pm$ 96.444 N.mm/mm vs Preexposed: $73.157 \pm 36.511$ N.mm/ $\mathrm{mm}$ and Pre- and Postexposed: $154.049 \pm 134.939$ N.mm/ $\mathrm{mm}$, mean difference $=418.2$ N.mm $/ \mathrm{mm}, 95 \%$ CI, 306.3$530.1 \mathrm{~N} . \mathrm{mm} / \mathrm{mm}$ and mean difference $=337.3 \mathrm{~N} . \mathrm{mm} / \mathrm{mm}$, 95\% CI, 188.8-485.9 N.mm/mm; p < 0. 01).

Conclusions Rats exposed to tobacco smoke showed delayed fracture healing and callus that was characterized by decreased maturity, density, and mechanical resistance, which was confirmed by all assessment methods of this study. Such effects were more evident when animals were exposed to tobacco smoke before and after the fracture. Future studies should be done in human passive smokers to confirm or refute our findings on fracture callus formation.

Clinical Relevance The potential hazardous effects of secondhand smoke on fracture healing in rodents should stimulate future clinical studies in human passive smokers.

\section{Introduction}

Tobacco smoke products have a negative effect on the skeleton as they are associated with osteoporosis [10, 18], loosening of osseous implants [12, 26], and impaired fracture healing $[1,16]$. One systematic review on the correlation between active tobacco smoking and bone healing for nonspinal orthopaedic interventions found tobacco smoke has an adverse effect on bone healing, and contributes to increased rates of delayed union and nonunion [25]. Patel et al. [25] also noted several biases related to study designs and settings such as the characteristics of participants, outcome measures, and the length of followup. They recommended that future studies should include more reliable methods of assessing smoking exposure such as measures of exhaled carbon monoxide and cotinine levels in blood or saliva.

Some clinical and experimental investigations have addressed primary exposure to mainstream tobacco smoke or nicotine administration. Secondhand smoke also may be a concern, as tobacco smoke is an important environmental air pollutant [6, 22]. Haley et al. [14] showed that hamsters exposed to sidestream cigarette smoke (smoke that passes from a cigarette into the surrounding air, rather than into the smoker's lungs) had an increased blood concentration of cotinine (a biomarker and major metabolite of nicotine). Although nonsmokers may be exposed to almost the same chemicals as active smokers [3], we were unable to find any studies correlating fracture healing and passive exposure to tobacco smoke.

Therefore, this study aims to explore the possible effects of passive inhalation of tobacco smoke on healing of a diaphyseal fracture in femurs of rats. Specifically, we hypothesized that secondhand exposure to tobacco smoke adversely affects fracture healing.

\section{Materials and Methods}

Our study was approved by the institutional animal ethical committee (protocol 139/2013). In the study, we used 41 Wistar female rats (Rattus norvegicus albinus) obtained from the Central Animals' Facility of the University of São Paulo, with an initial mean body mass and SD of $150 \pm 10$ $\mathrm{g}$ (young adults). The rats were housed in metabolic cages at room temperature (between $22^{\circ}$ and $24^{\circ} \mathrm{C}$ ) under $12-$ hour light and dark cycles, a relative air humidity of $55 \%$ $( \pm 10 \%)$, and with free access to food and water.

The animals were randomly assigned to one of the following three groups: (1) Control rats $(n=10)$ were temporarily sham-exposed for 28 days in smoke-free chambers. Then, a fracture was produced in the right femur, and sham exposure continued for an 28 additional days; (2) Preexposed rats $(n=15)$ received temporary exposure to tobacco smoke inhalation for 28 days before sustaining a fracture of the femur, but no exposure after this fracture; and (3) Pre- and Postexposed rats $(n=16)$ received temporary exposure to tobacco smoke inhalation for 28 days before sustaining a fracture of the femur, which was continued along the 28 days postfracture. The concentration of carbon monoxide was measured while animals remained in the smoke chamber (ITMCO-1500; Instrutemp, São Paulo, SP, Brazil).

The equipment that was used to expose the animals to tobacco smoke had four inhalation cylindrical chambers $(7.0 \mathrm{~cm}$ in diameter $\times 23.0 \mathrm{~cm}$ in length; total volume 885 $\mathrm{cm}^{3}$ ). One extremity of the chamber was open and was used for animal manipulation. The opposite extremity was funnel-shaped and connected to a mechanical pump (inflow/outflow). The tobacco smoke was provided by one regular-sized filtered cigarette (Marlboro; Philips Morris International, Santa Cruz, RS, Brazil), yielding $10 \mathrm{mg}$ tar 
and $0.8 \mathrm{mg}$ nicotine, coupled to a peristaltic pump that aspirated the smoke, drove it into a distributing chamber, and then directed it to the animal chambers (Fig. 1). This set was placed inside an insulating outer box and exhaust for the smoke to exit the chamber. Puffing was mimicked by alternating injections of fresh air (30 seconds) and smoke air (15 seconds). Animals were placed inside the exposure chambers with the muzzle directed to the cylindrical extremity and held in place by a restrictor. Therefore, smoke was delivered to the muzzle. Smoke inhalation was initiated by burning one cigarette twice each day (morning and afternoon; 6-hour interval) for seven consecutive days. Each complete burning took 5 minutes. After this acclimatization period, rats were exposed to the smoke of two cigarettes in the morning and two more in the afternoon. Sham-exposed animals were placed in individual chambers not contaminated by smoke, under the same conditions of the treated animals but with intermittent puffs of fresh inflow and outflow air. The carbon monoxide concentration in the animal chambers was similar and ranged from $337.75 \mathrm{ppm}$ to $340.43 \mathrm{ppm}$. The cotinine levels of exposed animals were increased in comparison to the control animals (Control: $0.05 \pm 0.06 \mathrm{ng} / \mathrm{mL}$ vs Preexposed: $3.77 \pm 0.86 \mathrm{ng} / \mathrm{mL}$ and Pre- and Postexposed: $12.93 \pm 1.72 \mathrm{ng} / \mathrm{mL}$, mean difference $=-4.132,95 \% \mathrm{CI}$, -5.196 to 3.068 and mean difference, $-11.45,95 \% \mathrm{CI}$, -12.64 to 10.26 ; $\mathrm{p}<0.01$ ), which is compatible with human secondhand smoker levels.

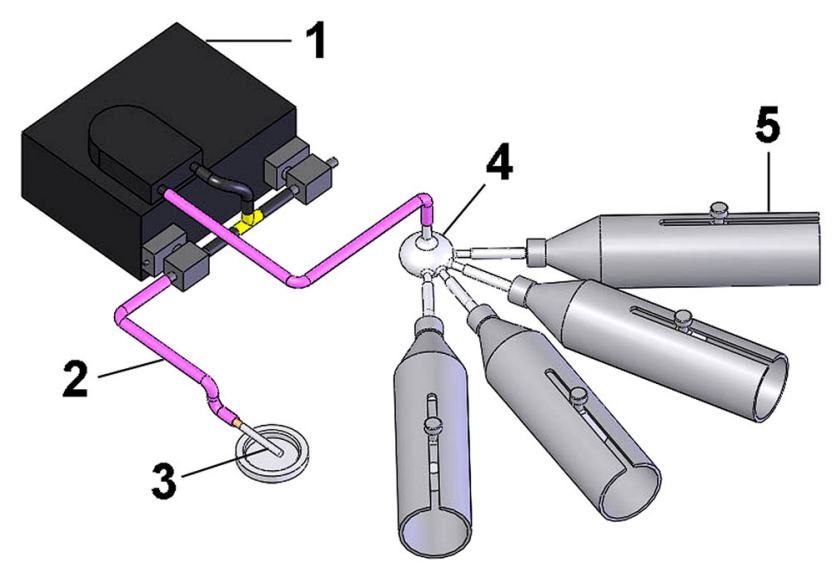

Fig. 1 A schematic of the device used to expose the animals to cigarette smoke is shown. The numbers on the schematic refer to the peristaltic pump (1), pipe (2), cigarette (3), spherical container for smoke distribution (4), and cylindrical tubes (5) where the animals were placed for tobacco exposure. The peristaltic pump aspirates the cigarette smoke, drives it to the distribution chamber, and the smoke then is distributed to the individual chambers.
Surgical Procedure

For the femoral fracture procedure, animals were anesthetized with a combination $(1: 1)$ of xylazine and ketamine $(0.1 \mathrm{mg} / 100 \mathrm{~g})$ injected intramuscularly, and the right pelvic limb was shaved. Next, the right thigh was restrained by two metallic supports [7]. The blunted blade of a guillotine apparatus was lowered onto the middle part of the thigh, and a vertical force was applied until an abrupt decrease in resistance occurred, indicating femur failure (fracture). Subsequently, the entire pelvic limb was cleansed with a $0.5 \%$ alcohol-based chlorhexidine antiseptic solution (Riohex; Rioquímica, São José do Rio Preto, SP, Brazil). A miniincision was made on the lateral surface of the middle-third of the thigh under ordinary aseptic and antiseptic surgical conditions. Deepening of the approach was made between the vastus lateralis and biceps femoris muscles until reaching the bone fragments and the fracture was partially exposed. Any fracture not located at the mid-shaft region or excessively fragmented was excluded (two main fragments and more than three intermediary small fragments). Then, the fracture was stabilized using a $1.0-\mathrm{mm}$ thick $\mathrm{K}$ wire inserted in the medullary canal of the proximal fragment until it protruded through the trochanteric region. The fracture then was reduced under direct vision and secured by advancing the $\mathrm{K}$ wire into the medullary canal of the distal fragment to the distal end of the femur. The excess wire length at the trochanteric region was cut off, bent, and buried beneath the muscle. The wound tissue was closed in layers, and the skin was sprayed with a solution to avoid self-mutilation (Adestro; Limpinho, Santos, SP, Brazil). Frontal and profile radiographs were obtained using a digital technique to check for adequacy of fracture reduction and fixation.

The rats were allowed to recover postoperatively in a warmed and protected environment. Diluted dipyrone solution was used as analgesic; it was injected subcutaneously every 12 hours during the immediate postoperative period. Analgesia was continued for 1 week with paracetamol diluted in drinking water. The surgically treated animals were examined daily to check the wound appearance, spontaneous activity, mobility, weightbearing, ROM of the knee, and food ingestion. The animals were kept in metabolic cages during the entire followup period.

Forty-one rats were used, but 14 were excluded (nine with inadequate fractures and five owing to $\mathrm{K}$ wire extrusion). We excluded fractures so comminuted that is was impossible to insert a $\mathrm{K}$ wire for stabilization. All cases of $\mathrm{K}$ wire extrusion occurred in the animals exposed to smoke either before, or before and after bone fracture. It is possible that bone-implant anchorage of the $\mathrm{K}$ wire was affected by exposure to tobacco smoke, thus causing pin loosening. The final number of rats included in the analysis 
therefore was 27, including nine from the control group, 11 from the group with preexposure, and seven from the group with pre- and postfracture exposure to tobacco smoke. Of the 14 excluded rats, 13 belonged to tobacco exposure groups, which may explain the poor bone quality leading to $\mathrm{K}$ wire loosening.

Euthanasia occurred 28 days after bone fracture in all groups with a lethal dose $(3.0 \mathrm{~mL} / 100 \mathrm{~g})$ of sodium thiopental (1.25\% solution) administered intraperitoneally. Soon afterward, blood samples were collected through cardiac puncture. The levels of cotinine were measured using gas chromatography (5890 Series 2; Hewlett-Packard, Palo Alto, CA, USA) with nitrogen-phosphorus. The fractured and nonfractured femurs were removed and dissected; the $\mathrm{K}$ wire was carefully removed, and the bones were kept moistened in saline. Since dual energy $x$-ray absorptiometry (DXA) was done immediately after euthanasia, bones were not stored elsewhere. For $\mu \mathrm{CT}$ assessment, bones were kept in $70 \%$ ethanol for a short period (no longer than 3 days after dissection). Immediately after $\mu \mathrm{CT}$ the bones were mechanically tested.

Assessment of Bone Mineral Density, Bone Mineral Content, and Area of Bone Callus

The analysis was done using DXA with a Lunar DPX-IQ densitometer (Lunar Version 4.7e; GE Healthcare, Little Chalfont, UK) $[7,17,19]$. The entire fractured femur was scanned and the bone mineral density ([BMD] in $\mathrm{g} / \mathrm{cm}^{2}$ ), bone mineral content ([BMC] in $\mathrm{g}$ ), and area $\left(\right.$ in $\mathrm{cm}^{2}$ ) were assessed over the full extent of the callus. The region of interest was manually drawn to include only the bone callus, thus providing the area of bone callus. BMD and BMC were automatically calculated by the attenuation of radiographs in bone tissue. The scanning reproducibility, which was $4 \%$, was assessed by the root mean square coefficient of variation.

Five femurs from each group (previously calculated by a statistic) were randomly selected and scanned using a $\mu \mathrm{CT}$ device (SkyScan 1174v2; Bruker-microCT, Kontich, Belgium) at $50 \mathrm{kV}$ with the aid of a 0.5 -mm-thick aluminum filter to optimize the contrast, a $360^{\circ}$-rotation step of $1^{\circ}$, three-frame averaging, and an isotropic resolution of 26.7 $\mu \mathrm{m}$. Images of each specimen were reconstructed with specific software (NRecon Version 1.6.3; Bruker-microCT). Bone callus containing woven bone was isolated from trabecular and cortical bone by manual drawing. The fracture callus was analyzed using specific software (CTAn Version 1.15.4; Bruker-microCT) for determining the total callus volume (in $\mathrm{mm}^{3}$ ) and the woven bone fraction that was expressed as a percentage of the callus volume. One hundred percent woven bone represents the case in which the woven bone equals the total callus volume. Bone callus also was qualitatively analyzed by images acquired with the DataViewer software (Bruker-microCT).

\section{Mechanical Testing}

After being scanned for microCT studies the bones were submitted to mechanical evaluation. The fractured and intact femurs underwent a three-point bending test using an EMIC $^{\circledR} 10000 \mathrm{~N}$ universal testing machine (EMIC, São José dos Pinhais, PR, Brazil) equipped with a 500-N load cell. For this, the femur was placed on two metal supports $14 \mathrm{~mm}$ apart with the anterior surface facing up. A downward vertical force was applied at the center of the callus (or mid-diaphysis in nonfractured femurs) with a speed of $1.0 \mathrm{~mm}$ per minute until mechanical failure of the femur occurred. A 5.0-N preloading force and 30-second accommodation time were used during the tests. For all tests the load-deflection curve was constructed and the maximum force (in N.mm) and stiffness (in N.mm/mm) calculated using specialized software (TESC 3.04; EMIC). Stiffness was calculated by the slope in the linear portion of the curve. During the test, specimens were sprayed with saline solution to prevent dehydration. Special attention was paid to the generated curve to identify any change in specimen position or bizarre curves that could indicate lack of reproducibility.

\section{Statistical Analysis}

We expressed all values as means $\pm \mathrm{SD}$. The normal distribution was checked with the Kolmogorov-Smirnov test. The comparison among groups was performed with oneway ANOVA and Dunnett's post test. The level of significance was established at 95\% $(\mathrm{p}<0.05)$. We performed the statistical tests and creation of graphics with GraphPad Prism, Version 5 (GraphPad software, San Diego, CA, USA).

\section{Results}

The preexposed animals showed a mean reduction of $34 \%$ in BMD and $36 \%$ in BMC compared with the control rats. Similarly, the pre- and postexposed rats showed a mean reduction of $52 \%$ in BMD and $64 \%$ in BMC compared with control rats (Fig. 2) (BMD: Control: $0.302 \pm 0.008 \mathrm{~g} /$ $\mathrm{cm}^{2}$ vs Preexposed: $0.199 \pm 0.008 \mathrm{~g} / \mathrm{cm}^{2}$ and Pre- and Postexposed: $0.146 \pm 0.009 \mathrm{~g} / \mathrm{cm}^{2}$, mean difference $=$ $0.103 \mathrm{~g} / \mathrm{cm}^{2}, 95 \% \mathrm{CI}, 0.094-0.112 \mathrm{~g} / \mathrm{cm}^{2}$ and mean difference $=0.156 \mathrm{~g} / \mathrm{cm}^{2}, 95 \%$ CI, $0.147-0.167 \mathrm{~g} / \mathrm{cm}^{2}$; 

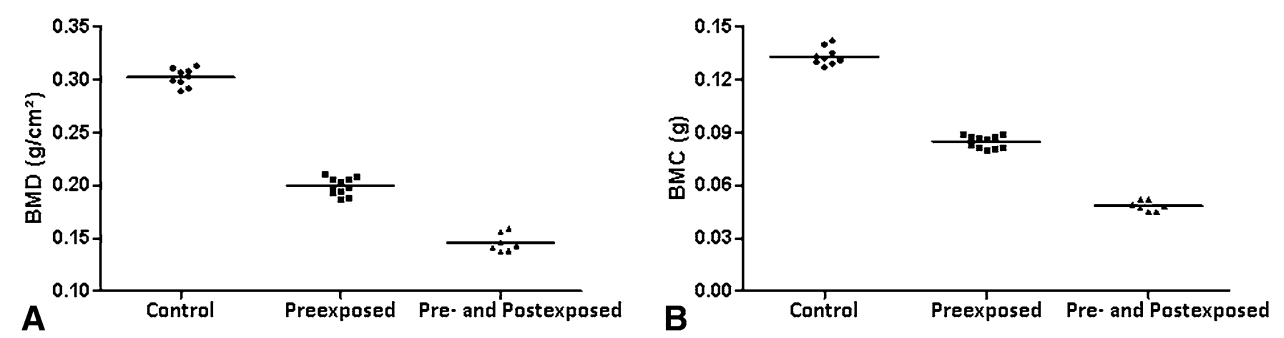

Fig. 2A-B DXA examination showed that (A) the BMD is decreased in the smoke-exposed animals. (B) The BMC also is reduced in the smokeexposed animals (Control vs Preexposed $\mathrm{p}<0.01$; Control vs Pre- and Postexposed $\mathrm{p}<0.01$ ).

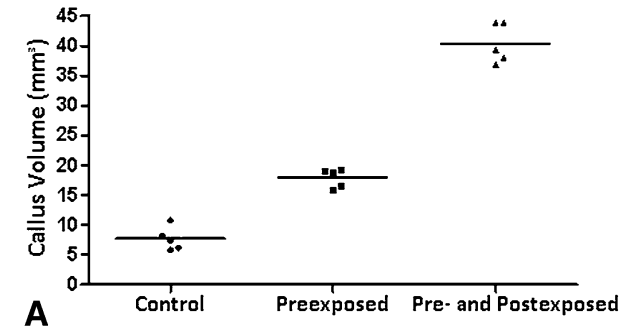

Fig. 3A-B (A) Although callus volume was increased in the smoke exposed animals, as determined by $\mu \mathrm{CT}$ analysis, $(\mathbf{B})$ the percentage of woven bone volume was decreased as a result of passive smoking

$\mathrm{p}<0.01$; BMC: Control: $0.133 \pm 0.005 \mathrm{~g}$ vs Preexposed: $0.085 \pm 0.0034 \mathrm{~g}$ and Pre- and Postexposed: $0.048 \pm 0.003$ $\mathrm{g}$, mean difference $=0.048 \mathrm{~g}, 95 \% \mathrm{CI}, 0.045-0.052 \mathrm{~g}$ and mean difference $=0.085 \mathrm{~g}, 95 \% \mathrm{CI}, 0.088-0.090 \mathrm{~g} ; \mathrm{p}<$ 0.01). Regions of interest varied according to the bone callus area (in $\mathrm{cm}^{2}$ ) (Control: $0.26 \pm 0.02 \mathrm{~cm}^{2}$; Preexposed: $0.38 \pm 0.01 \mathrm{~cm}^{2}$; Pre- and Postexposed: $0.53 \pm 0.01$ $\mathrm{cm}^{2}$ ).

The three-dimensional analysis of $\mu \mathrm{CT}$ showed that preexposed animals had an increase of $81 \%$ in volume in comparison with the tobacco-free rats (Fig. 3A) (Callus volume: Control: $7.656 \pm 1.963 \mathrm{~mm}^{3}$ vs Preexposed: $17.952 \pm 1.600 \mathrm{~mm}^{3}$ and Pre- and Postexposed: $40.410 \pm$ $3.340 \mathrm{~mm}^{3}$, mean difference $=-10.30 \mathrm{~mm}^{3}, 95 \% \mathrm{CI}$, -14.12 to $6.471 \mathrm{~mm}^{3}$ and mean difference $=-32.75 \mathrm{~mm}^{3}$, $95 \% \mathrm{CI},-36.58$ to $28.93 \mathrm{~mm}^{3}$; $\mathrm{p}<0.01$ ). However, the percentage of woven bone in callus decreased $60 \%$ for animals previously exposed and $81 \%$ for those pre- and postexposed (Fig. 3B) (Woven bone fraction: Control: $42.076 \pm 3.877 \%$ vs Preexposed: $16.655 \pm 3.021 \%$ and Pre- and Postexposed: $8.015 \pm 1.565 \%$, mean difference $=$ $0.103 \%, 95 \%$ CI, $0.094-0.112 \%$ and mean difference, $0.156 \%, 95 \%$ CI, $0.147-0.166 \%$; $p<0.01$ ).

Microtomographic images of the bone callus showed important differences among the three groups (Fig. 4). While control animals displayed bone callus formation with the presence of newly formed trabecular bone, tobacco exposure caused delayed bone healing with bone callus mostly formed by nonosseous tissue.

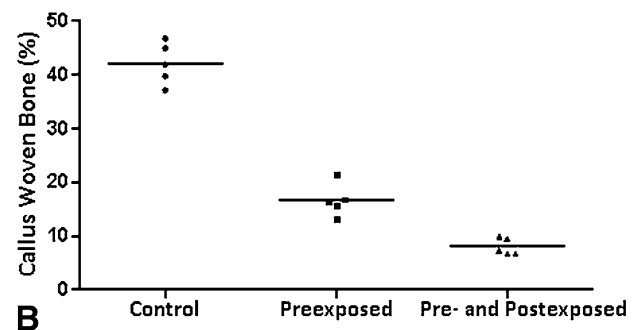

(less mineralized bone callus), underlying the impaired bone healing in the tobacco exposed groups (Control vs Preexposed $\mathrm{p}<0.01$; Control vs Pre- and Postexposed $\mathrm{p}<0.01$ ).

Mechanical testing showed that preexposed rats showed a decreased callus strength of $65 \%$, whereas the pre- and postexposed rats showed a decrease of $71 \%$ (Fig. 5A) (Maximum force: Control: $427.122 \pm 63.952$ N.mm vs Preexposed: $149.230 \pm 67.189$ N.mm and Pre- and Postexposed: $123.130 \pm 38.206$ N.mm, mean difference $=$ 277.9 N.mm, 95\% CI, 201.1-354.7 N.mm and mean difference $=304$ N.mm, 95\% CI, 213.2-394.8 N.mm; p < $0.01)$. Likewise, callus stiffness was reduced $85 \%$ in the preexposed animals and $69 \%$ in the pre- and postexposed animals (Fig. 5B) (Stiffness: Control: $491.397 \pm 96.444$ N.mm/mm vs Preexposed: $80.462 \pm 82.688$ N.mm $/ \mathrm{mm}$ and Pre- and Postexposed: $154.049 \pm 134.939$ N.mm/mm, mean difference $=418.2 \mathrm{~N} . \mathrm{mm} / \mathrm{mm}, 95 \%$ CI, 306.3-530.1 N.mm $/ \mathrm{mm}$ and mean difference $=337.3 \mathrm{~N} . \mathrm{mm} / \mathrm{mm}, 95 \%$ CI, 188.8-485.9 N.mm/mm; p < 0.01).

Mechanical testing also was performed in nonfractured bones (Fig. 6). Tobacco exposure decreased bone strength and it seems to be time-dependent. Twenty-eight days of exposure (Preexposed group) decreased maximum force in $19 \%$ and stiffness in 27\%. Fifty-six days of exposure (Preand Postexposed group) decreased maximum force in 33\% and stiffness in 45\% (Maximum force: Control: $151.941 \pm$ 9.219 N.mm vs Preexposed: $122.856 \pm 5.009$ N.mm and Pre- and Postexposed: $102.106 \pm 4.186$ N.mm, mean difference $=29.08$ N.mm, 95\% CI, 22.1-33.1 N.mm and mean difference $=49.8$ N.mm, 95\% CI, 42.0-57.6 N.mm; $\mathrm{p}<0.01$. Stiffness: Control: $393.280 \pm 13.014$ N.mm vs Preexposed: $289.534 \pm 11.626$ N.mm and Pre- and 

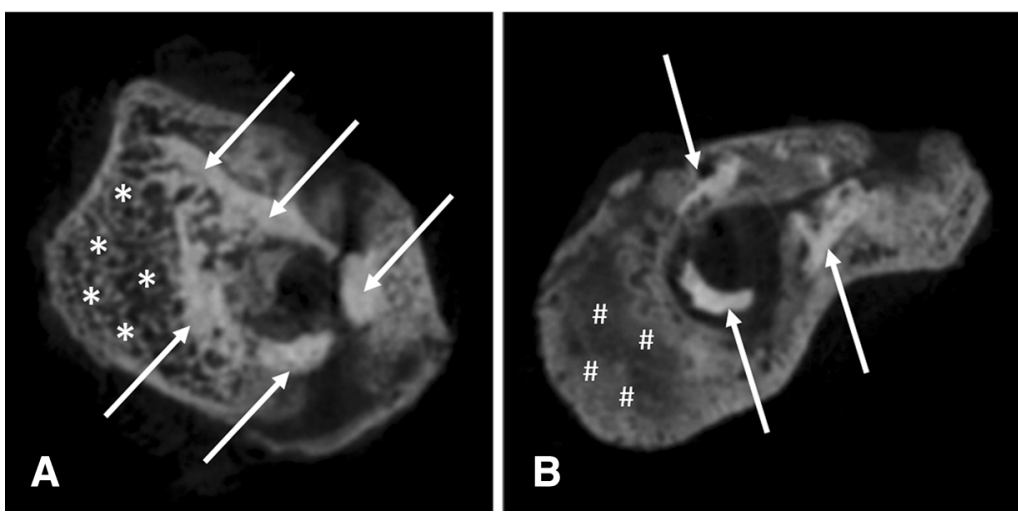

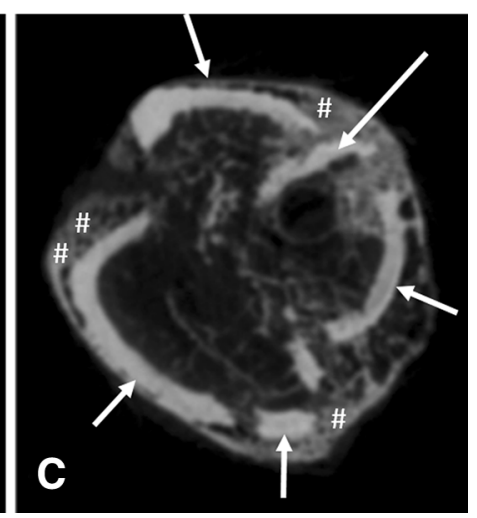

and postexposure also showed impaired bone healing, but to a greater degree than with preexposure to tobacco smoke. The arrows indicate cortical bone, the asterisks indicate woven bone, and the hashtags indicate immature nonosseous tissue in bone callus.
Fig. 5A-B (A) Tobacco smoke exposure reduced callus resistance (maximum force). (B) The callus stiffness also was reduced by the smoke exposure (Control vs Preexposed $\mathrm{p}<0.01$ Control vs Pre- and Postexposed $\mathrm{p}<0.01)$.

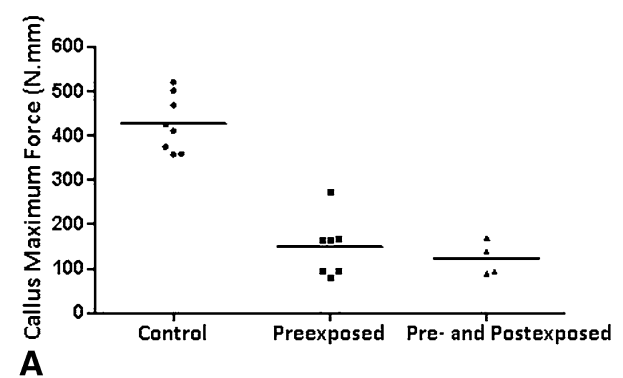

A

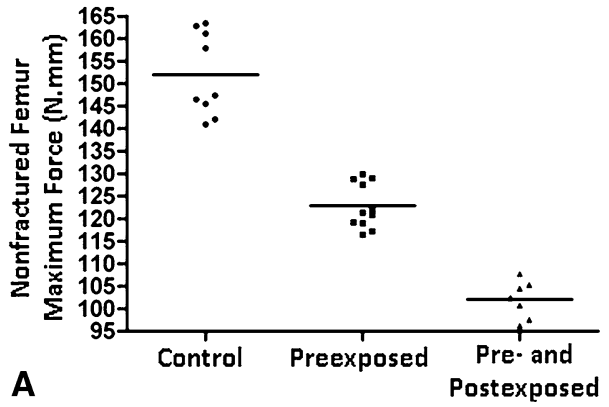$$
\text { A }
$$

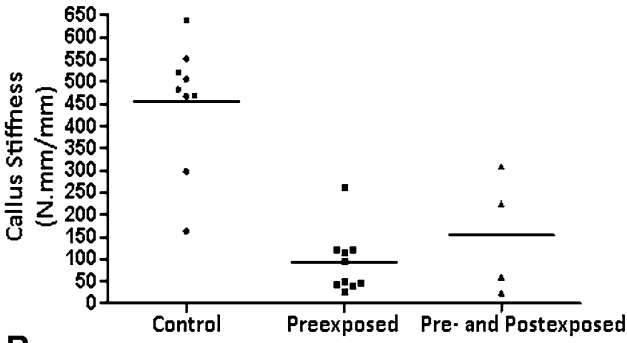

B

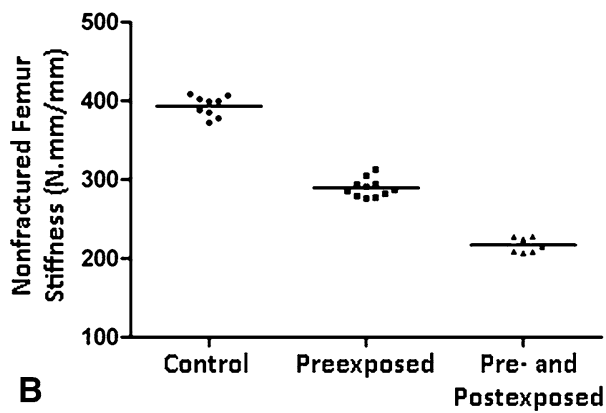

Fig. 6A-B (A) Tobacco smoke exposure reduced bone maximum force. (B) Bone stiffness was also reduced by the smoke exposure (Control vs Preexposed $p<0.01$; Control vs Pre- and Postexposed $\mathrm{p}<0.01$ ).
Fig. 4A-C (A) Control rats showed normal bone callus formation with the presence of newly formed trabecular bone. (B) Rats preexposed to tobacco smoke showed delayed bone healing with bone callus mostly formed by nonosseous tissue. (C) Rats with pre- 
resistant callus. In addition, our results suggest that the harmful effects are dose dependent. Furthermore, tobacco exposure also impaired mechanical strength of intact bone, thus indicating an impairment of the bone tissue as well.

Our study has several limitations. It focuses on the relationship between secondhand tobacco smoke exposure and fracture healing. However, no standardized cutoff range for serum cotinine levels in different animal species is available. Therefore, we adopted the human cotinine levels ranging from 2.1 to $17.5 \mathrm{ng} / \mathrm{mL}$, which are comparable to the levels observed in human secondhand smokers, to characterize our rats as passive smokers [20]. Consequently, it is not reliable to make a strict transposition between the exposure used in the current study and human indoor exposure. The extent of exposure that was required to produce cotinine levels was determined previously in a pilot study (unpublished data). The animal daily exposure to tobacco smoke varies widely in different protocols and there is no standardized model, but the exposure we used was lower than the exposure in another study [23]. However, Coggins examined chronic smoke exposure to determine carcinogenic effects [9] and to mimic other conditions experienced by heavy human smokers. We, however, did not aim to mimic heavy smokers but ordinary individuals (passive smokers) who are exposed to a smoke environment attributable to active smokers. Another limitation of our model is that the smoke was delivered to the animal muzzle and may not reproduce passive exposure. Some models use collective compartments in which the smoke is first delivered to the ambient space before being inhaled. This type of exposure may be more realistic, but presents the inconvenience of impregnating the animal fur with tobacco derivatives and nicotine or tar substances may be ingested with self-cleaning [32]. Although we studied the effects of mainstream smoke on bone tissue, we are unsure if our results would be different if we had used sidestream smoke once several factors were involved (ie, compound composition and concentration, filters, and smoke exposure).

Young adult female rats were used in our study. Female animals are easier to handle in a laboratory environment and can share collective cages. We are unaware of any study that compares smoke exposition among male and female animals, but a study with human volunteers did not show any difference between the genders [4]. Young adult rats were chosen because our pilot study showed that older animals had an unacceptable rate of mortality, mostly after fracture production. Despite the extensive use of rats in fracture investigation, it has been claimed that bone healing in such animals may not exactly mimic human fracture healing, as the rat diaphyseal cortex does not have Haversian osteons [15]. However, all the other stages involved in osteochondral ossification are shared between humans and rats. In addition, the fracture model used in our study differs from the original description by Bonnarens and Einhorn [5], as a pin was not inserted before fracturing the bone, therefore there was no control of the applied force. Although our model has a limitation owing to the production of less-standardized fractures, it has the offsetting advantage that it produces injuries that better mimic real fractures, with periosteal stripping and bone displacement. We assessed the nonfractured femur and bone callus strength with a three-point bending test because we aimed to evaluate the bone callus.

Fracture union is a cascade of events that demands a suitable microenvironment for cell differentiation and tissue formation. Successful fracture healing requires mechanical stability, the presence of osteogenic cells, an osteoconductive structure, appropriate growth factors [13], and sufficient blood supply. Thus, adequate systemic and local conditions are required to provide uneventful fracture consolidation.

Nicotine is a toxic and major compound found in tobacco smoke. Its hepatic metabolism yields cotinine, a major metabolite, which is more stable and has a longer half-life than nicotine. These conditions favor the use of cotinine as a biologic marker for assessment of exposure to tobacco smoke $[8,11]$ and serve as an alert regarding the persistence of the harmful effect of tobacco smoke inhalation. Several stages of the fracture healing process can be adversely affected by products of tobacco smoke. Nicotine is a potent vasoconstrictor and has a direct effect on microcirculation and angiogenesis [2]; moreover, the effects of nicotine appear to involve more than just local vasoconstriction. Nicotine also may interfere with osteoblastic activity $[21,31]$ and negatively affect differentiation and activation of osteoclasts [33], thus hampering bone modulation. At the molecular level, nicotine may affect gene expression and therefore compromise type I and type II collagen formation [29].

Our study did not show development of nonunions as did that of Raikin et al. [27] in rabbits that underwent tibial osteotomy and plate fixation, and received subcutaneous infusion of cotinine that corresponded to levels of heavy smokers. Yet, our results clearly show that the exposed rat had adversely affected callus as shown by lower bone densities and mineral contents. Further, $\mu \mathrm{CT}$ analysis showed that although there was a higher volume of callus formation in the exposed animals, the callus had a lower percentage of bone tissue formation (woven bone), which suggests poor healing. The mechanical analysis also expressed a less-resistant callus. Therefore, all three methods of analysis used in our investigation indicated impairment of fracture healing attributed to inhalation of secondhand tobacco smoke. Similar results were found by Raikin et al. [27], who conducted an experimental study in 
which rabbits underwent tibial osteotomy. The animals received nicotine subcutaneously, thus reaching blood levels compatible with active smoking, and there was no exposure to the other components of tobacco smoke. In contrast, Hastrup et al. [15] found that either ingestion, or pump administration of an aqueous tobacco extract improved the torsional properties of healing fractures. Nevertheless, the tobacco extract was obtained from an aqueous solution of noncombusted tobacco that certainly contained different substances than tobacco smoke, which may help to explain this unusual and seemingly contradictory finding.

Our results suggest that exposure to secondhand tobacco smoke may have a potential hazardous effect on bone callus quality in rats. Future studies should encompass human passive smokers to confirm or refute our findings on fracture callus formation and further experimental investigations should search for a more-realistic model of tobacco smoke exposure.

Acknowledgments We thank Rafael M. Reis MSc (Division of Radiology, School of Medicine of Ribeirão Preto, University of São Paulo, Brazil) for statistical counseling, and the Laboratory of Bioengineering, School of Medicine of Ribeirao Preto, University of São Paulo, Brazil.

\section{References}

1. Argintar E, Triantafillou K, Delahay J, Wiesel B. The musculoskeletal effects of perioperative smoking. J Am Acad Orthop Surg. 2012;20:359-363.

2. Balatsouka D, Gotfredsen K, Sorensen L, Lindh CH, Berglundh T. Effect of systemic administration of nicotine on healing in osseous defects: an experimental study in rabbits. Part II. Clin Oral Implants Res. 2006;17:488-494.

3. Barnoya J, Glantz SA. Cardiovascular effects of secondhand smoke: nearly as large as smoking. Circulation. 2005;111:26842698.

4. Benowitz NL, Jacob P 3rd. Daily intake of nicotine during cigarette smoking. Clin Pharmacol Ther. 1984;35:499-504.

5. Bonnarens F, Einhorn TA. Production of a standard closed fracture in laboratory animal bone. J Orthop Res. 1984;2:97-101.

6. Borland R, Fagerstrom K, Foulds J, McNeill A, Ramstrom L. FCTC background report on smokeless tobacco is incompatible with WHO scientific reports. Addiction. 2011;106:225-227.

7. Butezloff MM, Zamarioli A, Leoni GB, Sousa-Neto MD, Volpon JB. Whole-body vibration improves fracture healing and bone quality in rats with ovariectomy-induced osteoporosis. Acta Cir Bras. 2015;30:727-735.

8. Chou SY, Hsu HH, Kuo HH, Kuo HW. Association between exposure to environmental tobacco smoke (ETS) and breastfeeding behaviour. Acta Paediatr. 2008;97:76-80.

9. Coggins CR. A review of chronic inhalation studies with mainstream cigarette smoke in rats and mice. Toxicol Pathol. 1998;26:307-314; discussion 315.

10. Cusano NE. Skeletal effects of smoking. Curr Osteoporos Rep. 2015;13:302-309.

11. Dempsey D, Jacob P 3rd, Benowitz NL. Accelerated metabolism of nicotine and cotinine in pregnant smokers. J Pharmacol Exp Ther. 2002;301:594-598.
12. Fini M, Giavaresi G, Salamanna F, Veronesi F, Martini L, De Mattei M, Tschon M. Harmful lifestyles on orthopedic implantation surgery: a descriptive review on alcohol and tobacco use. $J$ Bone Miner Metab. 2011;29:633-644.

13. Giannoudis PV, Einhorn TA, Marsh D. Fracture healing: the diamond concept. Injury. 2007;38(suppl 4):S3-6.

14. Haley NJ, Adams JD, Alzofon J, Hoffmann D. Uptake of sidestream smoke by Syrian golden hamsters. Toxicol Lett. 1987;35:83-88.

15. Hastrup SG, Chen X, Bechtold JE, Kyle RF, Rahbek O, Keyler DE, Skoett M, Soeballe K. Effect of nicotine and tobacco administration method on the mechanical properties of healing bone following closed fracture. J Orthop Res. 2010;28:12351239.

16. Hernigou J, Schuind F. Smoking as a predictor of negative outcome in diaphyseal fracture healing. Int Orthop. 2013;37:883887.

17. Hind K, Oldroyd B, Truscott JG. In vivo precision of the GE Lunar iDXA densitometer for the measurement of total body composition and fat distribution in adults. Eur J Clin Nutr. 2011;65:140-142.

18. Hopper JL, Seeman E. The bone density of female twins discordant for tobacco use. N Engl J Med. 1994;330:387-392.

19. Knapp KM, Welsman JR, Hopkins SJ, Shallcross A, Fogelman I, Blake GM. Obesity increases precision errors in total body dualenergy x-ray absorptiometry measurements. $J$ Clin Densitom. 2015;18:209-216.

20. Lindqvist R, Lendahls L, Tollbom O, Aberg H, Hakansson A. Smoking during pregnancy: comparison of self-reports and cotinine levels in 496 women. Acta Obstet Gynecol Scand. 2002;81:240-244.

21. Ma L, Zwahlen RA, Zheng LW, Sham MH. Influence of nicotine on the biological activity of rabbit osteoblasts. Clin Oral Implants Res. 2011;22:338-342.

22. Moritsugu KP. The 2006 Report of the Surgeon General: the health consequences of involuntary exposure to tobacco smoke. Am J Prev Med. 2007;32:542-543.

23. Numaguchi S, Esumi M, Sakamoto M, Endo M, Ebihara T, Soma $\mathrm{H}$, Yoshida A, Tokuhashi Y. Passive cigarette smoking changes the circadian rhythm of clock genes in rat intervertebral discs. $J$ Orthop Res. 2016;34:39-47.

24. Oberg M, Jaakkola MS, Woodward A, Peruga A, Pruss-Ustun A. Worldwide burden of disease from exposure to second-hand smoke: a retrospective analysis of data from 192 countries. Lancet. 2011;377:139-146.

25. Patel RA, Wilson RF, Patel PA, Palmer RM. The effect of smoking on bone healing: a systematic review. Bone Joint Res. 2013;2:102-111.

26. Pereira ML, Carvalho JC, Peres F, Gutierres M, Fernandes MH. Behaviour of human osteoblastic cells cultured on plasmasprayed titanium implants in the presence of nicotine. Clin Oral Implants Res. 2008;19:582-589.

27. Raikin SM, Landsman JC, Alexander VA, Froimson MI, Plaxton NA. Effect of nicotine on the rate and strength of long bone fracture healing. Clin Orthop Relat Res. 1998;353:231-237.

28. Rubenstein D, Jesty J, Bluestein D. Differences between mainstream and sidestream cigarette smoke extracts and nicotine in the activation of platelets under static and flow conditions. Circulation. 2004;109:78-83.

29. Theiss SM, Boden SD, Hair G, Titus L, Morone MA, Ugbo J. The effect of nicotine on gene expression during spine fusion. Spine (Phila Pa 1976). 2000;25:2588-2594.

30. WHO. WHO urges more countries to require large, graphic health warnings on tobacco packaging: the WHO report on the global tobacco epidemic, 2011 examines anti-tobacco mass-media campaigns. Available at: http://www.who.int/mediacentre/news/ 
releases/2011/tobacco_20110707/en/. Accessed October 14, 2016.

31. Wing KJ, Fisher CG, O'Connell JX, Wing PC. Stopping nicotine exposure before surgery: the effect on spinal fusion in a rabbit model. Spine (Phila Pa 1976). 2000;25:30-34.

32. Wright JL, Cosio M, Churg A. Animal models of chronic obstructive pulmonary disease. Am J Physiol Lung Cell Mol Physiol. 2008;295:L1-15.
33. Yuhara S, Kasagi S, Inoue A, Otsuka E, Hirose S, Hagiwara H. Effects of nicotine on cultured cells suggest that it can influence the formation and resorption of bone. Eur J Pharmacol. 1999;383:387-393. 